\title{
Acne keloidalis nuchae: prevalence, impact, and management challenges
}

\author{
Adebola Ogunbiyi \\ Dermatology Unit, Department \\ of Medicine, College of \\ Medicine, University of Ibadan, \\ University College Hospital Ibadan, \\ Oyo State, Nigeria
}

This article was published in the following Dove Press journal:

Clinical, Cosmetic and Investigational Dermatology

14 December 2016

Number of times this article has been viewed

Correspondence: Adebola Ogunbiyi Dermatology Unit, Department of Medicine, College of Medicine, University of Ibadan, University College Hospital Ibadan, Queen Elizabeth Road, Ibadan, Oyo State, Nigeria

Tel +2348033353170

Email adebolaogunbiyi@yahoo.com

\begin{abstract}
Acne keloidalis nuchae $(\mathrm{AKN})$ also known as folliculitis keloidalis nuchae (FKN) is a chronic form of scarring folliculitis seen mostly in men of African descent. The term AKN is commonly used even though the condition is not a keloid, and the affected individuals do not have a tendency to develop keloids in other areas of the body. It is seen in post pubertal men and is rare after the age of 55 years. A few cases have been reported in females. which has been classified as a primary cicatricial alopecia since the exact cause of acne keloidalis (AK) remains unknown. However, a few inciting agents have been suggested which include androgens, inflammation, infection, trauma, genetics, and ingrowing hairs. AK shares some similar features with other forms of cicatricial alopecia and may occur together. Papules, pustules, and sometimes tumorous masses in the nuchal or occipital regions of the scalp hence the name "bumps" evolved in the environment. Despite its common occurrence, only a few seek help in hospital when lesions start to unsightly affect the individual's quality of life. The presences of the keloidal lesions are more stressful compared to the resulting alopecia. Various attempts to reduce the bumps with corrosives, acids, and car engine oils lead to larger lesions or unsightly scars. Active lesions produce bleeding during haircuts. This is worrisome as a couple of individuals with active AK share shaving instruments at the barber shop and are at risk of acquiring or transmitting blood-borne infections. There is an urgent need to encourage safe shaving habits and treatment of lesions at onset so as to prevent unsightly lesions.
\end{abstract}

Keywords: scarring alopecia, clinical features, treatment challenges

\section{Introduction}

Acne keloidalis nuchae (AKN) also known as folliculitis keloidalis nuchae (FKN) is one of the chronic forms of scarring folliculitis seen mostly in men of African descent. ${ }^{1}$ Although the term "folliculitis keloidalis nuchae" captures the follicular nature of the disorder and is preferred by some, the lesions develop past the nuchal area suggested by the terminology. The term AKN is commonly used although it is generally agreed that the condition is not a keloid, and affected individuals do not have a tendency to develop keloids in other areas of the body. Acne keloidalis (AK) lesions do not have histological features suggestive of a keloids. ${ }^{2}$

Hebra in 1860 first used the terminology sycosis framboesiformis although it had been described as a distinct entity in the late 1800s. ${ }^{3}$ In 1869, Kaposi referred it to as dermatitis papillaris capillitii, and in 1872, Bazin coined the term AKN. ${ }^{4}$ The exact cause of AKN remains unknown. The inciting agents appear to be multifactorial with various factors such as androgens, inflammation, infection, trauma, genetics, and 
ingrowing hairs being implicated. It shares some similar features with other forms of cicatricial alopecia and may occur together in the same individual. It has been classified as a mixed form of the primary cicatricial alopecia by the North American Hair Research Society. ${ }^{5}$ It is characterized by papules, pustules, and sometimes tumorous masses in the nuchal or occipital regions of the scalp hence the name "bumps" evolved in the environment. ${ }^{6}$ Despite its common occurrence, treatment may be challenging. This review highlights the epidemiology, clinical features, impact, and treatment challenges.

\section{Epidemiology}

AKN occurs majorly in those of African descent. It has been reported in a few Caucasians and other ethnic groups. ${ }^{7}$ It is predominantly a disorder of males although there are a few reports in females with a male to female ratio of $20: 1 .^{8,9}$ Reports from Nigeria give a prevalence ranging from $0.7 \%$ to $9.4 \%,{ }^{10-12}$ while in Benin in West Africa the prevalence is $0.7 \% .{ }^{13}$ In South Africa, a prevalence of $4.7 \%$ was seen in boys in their last year of school and $10.5 \%$ in older men. ${ }^{14}$ In African-Americans, the reported prevalence ranges from $0.5 \%$ to $13.6 \% .^{5,16}$ The latter was in American footballers who wore headgears for protection. Their Caucasian counterparts wearing the same headgears did not develop AKN.

\section{Pathogenesis}

\section{Hormonal factors}

AKN occurs mainly in men and rarely in females, suggesting that androgens may play a vital role directly or indirectly. It is rare before puberty and rarely develops after the age of 55 years. ${ }^{6}$ Despite the mandatory practice of regular shave haircuts for children in public schools, AKN is not seen as it rarely exists before puberty. Related to this may be an increase in the activity of the sebaceous glands, androgen receptor sensitivity of the follicles, and the effect of the increase in hormone levels itself. ${ }^{17}$

Genetic considerations in etiology have emanated from the fact that AKN occurs mainly in those of African descent. This has been associated with the kinky nature of the African hair and the curvature of the hair follicle in the skin. The sharp cut end of the terminal curly or kinky African hair has been known to produce extrafollicular and transfollicular penetration of the skin leading to ingrown hairs and thus psuedofolliculitis barbae in the beard area. ${ }^{18}$ This was also hypothesized as a possible etiology for AKN, where a haircut would stimulate some irritation of the follicles through ingrown hairs leading to chronic inflammation of the follicles in the nuchal area. However, histology of early lesions of AK does not suggest that ingrowing hairs stimulate the inflammation in AKN. ${ }^{19}$ Dermoscopic findings in patients with AKN also do not show ingrown hairs unlike in patients with pseudofolliculitis barbae (personal observation). There is also no reported association between the occurrence of pseudofolliculitis barbae and $\mathrm{AK}$ in many individuals. ${ }^{20}$

It is important to note, however, that symptoms do develop within hours to days of a haircut, similar to what obtains with psuedofolliculitis barbae. The exact mechanism played by haircut in its pathogenesis remains unclear. How does it set up a localized mechanical irritation with subsequent inflammation? Chronic irritation from shirt collars, caps, helmets, and wooden combs have all been implicated in the pathogenesis of AKN, but not proven. The restriction of the consequence of the mechanical irritation to the nuchal and occipital area is still unclear. However, it is clear that the aforementioned factors may sustain chronic irritation of the already ongoing folliculitis. It has also been suggested that shaving-induced trauma may also lead to abnormal keratin expression in individuals who experience FKN as seen in pseudo folliculitis barbae. ${ }^{21}$

Inflammation is central to the pathogenesis of AKN; however, whether it is a primary or secondary feature is not clear. Earlier reports had suggested that AKN was a form of mechanically induced folliculitis. However, AK has been classified as a primary form of inflammatory scarring alopecia in the absence of convincing inciting agents. Sperling et $\mathrm{al}^{19}$ and Herberg et $\mathrm{al}^{22}$ have suggested that a possible pathogenic mechanism based on histology of involved and noninvolved skin would be inflammation of single or follicular units resulting from inflammatory cells attracted to antigens within the follicular unit or on the epithelium resulting in destruction or repair of the pilosebaceous unit. ${ }^{19,22}$ Potential intrafollicular antigens include sebum, desquamated keratinocytes, demodex, normal skin flora, and their metabolic by-products. In view of the hair grooming practices of Africans, cosmetics should also be considered. The inflammation causes edema resulting in the small papules seen in the early phase of the disorder. As with other cicatricial alopecia, sebaceous glands are reduced in number. Whether the sebaceous gland is a target of the inflammatory process or gets destroyed in the process is not clear. ${ }^{23}$

The role of bacteria especially Staphylococcus aureus and fungal elements such as malassezia in AKN pathogenesis appears secondary. Chronic low-grade infection, autoimmunity, and use of some mediation such as cyclosporine, diphenylhydantoin, and carbamazepine have been implicated in some patients. ${ }^{24,25}$ 
Reasons for localization of AKN to the nuchal and occipital areas remain unclear. This may be because of an increase in mast cells and dermal papillary dilatation in the area. ${ }^{17}$ Other reasons suggested by those with $\mathrm{AKN}$ include friction from scalp skin folds in the occipital region and possibly obesity. A previous report had suggested that AKN might be a cutaneous manifestation of the metabolic syndrome; however, this is yet to be confirmed on a larger scale. ${ }^{26}$

\section{Histopathology}

The histopathology of AKN is variable and depends on the duration and activity of the lesion. Secondary features such as bacterial infections, the presence of sinuses or the associated forms of scarring form of alopecia may contribute to the histological findings. Findings are not pathognomonic and may be seen in other forms of scarring alopecia. Perilesional and normal appearing skin may show evidence of low-grade chronic inflammation. The most common finding as reported by Sperling et $\mathrm{al}^{19}$ includes perifollicular chronic inflammation with lymphocytic and plasmacytic cells that is most intense at the level of the isthmus and lower infundibulum, lamellar fibroplasia most marked at the level of the isthmus, and complete disappearance or destruction of the sebaceous glands associated with inflamed or destroyed follicles. Thinning of the follicular epithelium may be seen at the level of the isthmus, and several hairs may be seen sharing the same infundibulum. Premature desquamation of the inner root sheet and destruction of the follicular epithelium with some retained hairs and granulomatous inflammation may be present. Hair follicles may be replaced by connective tissue. Some of the ealier findings may be seen in other forms of scarring alopecia, thus clinical features may be very useful for diagnosis.

\section{Clinical features}

$\mathrm{AKN}$ is a chronic disorder of hair follicles in the nuchal and/or occipital area of the scalp that starts after puberty. The disease onset is characterized by the development of varying sizes of papules and/or pustules on the nuchal or/ and occipital region spreading laterally or sometimes all the way toward the vertex (Figure 1). The onset is usually preceded by pruritus a few hours to days after a haircut or some form of mild irritation from use of a headwear such as a sports helmet. Some young men avoid cutting the hair in the occipital region, which is believed to prevent its occurrence or reoccurrence. Pruritus, pain, and contact bleeding are common in active lesions. Bleeding may stain shirt collars, which are worn with the intention of reducing the visibility

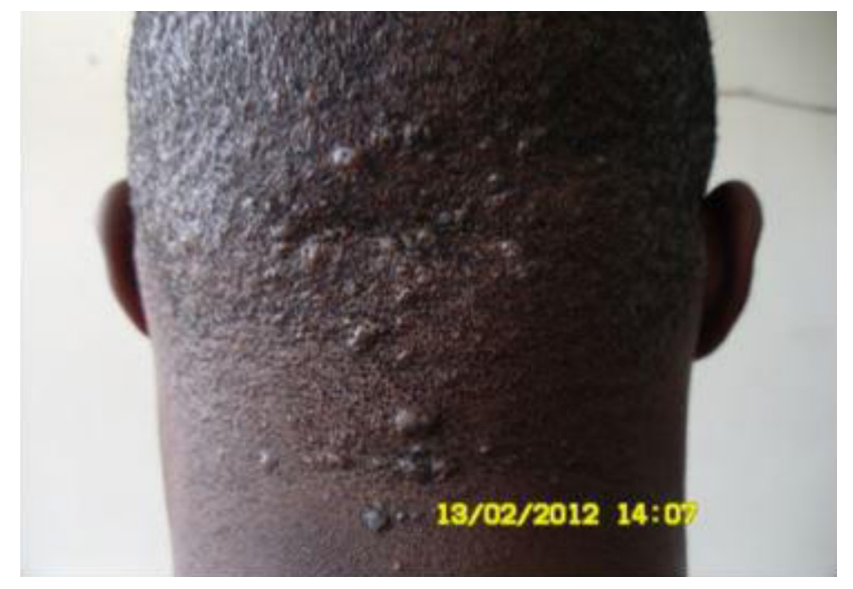

Figure I Papules of varying sizes on nuchal and occipital area.

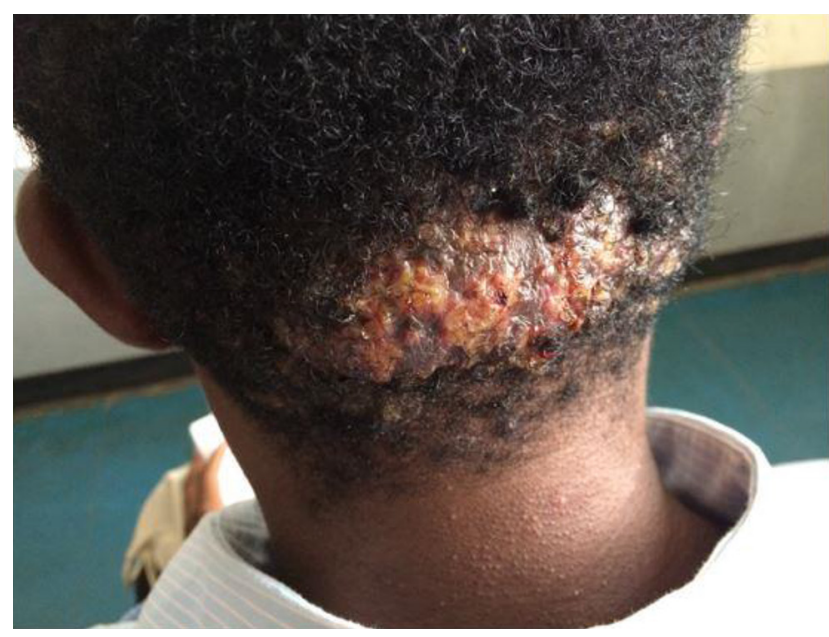

Figure 2 Acne keloidalis: plaque form with secondary infection.

of the lesions. Bleeding of some papules can be seen during a haircut especially at the barbers as the papules make shaving of the area difficult. This is worrisome as a significant number of people still share clippers at the barbers and are at the risk of acquiring blood-borne infections such as viral hepatitis and human immunodeficiency virus (HIV) among others. ${ }^{27,28}$ Pruritus sets up a cycle of itch, scratch, irritation, and inflammation. Secondary bacterial infection is common predisposing to pustules, sinuses and abscesses, and larger lesions affecting the patients' self-esteem (Figure 2). In few individuals, there may be an initial generalized folliculitis of the scalp healing with residual lesions of $\mathrm{AKN}$ on the occipital region, which then tend to recur. Recurrence of the folliculitis then leads to patchy scarring alopecia. Some individuals may have associated folliculitis decalvans (Figure 3 ). The cause of the tumorous lesions in some individuals is not clear as the size and extent of the lesions in AKN do not seem to be determined by the duration of the illness as some lesions are known to development rapidly into 


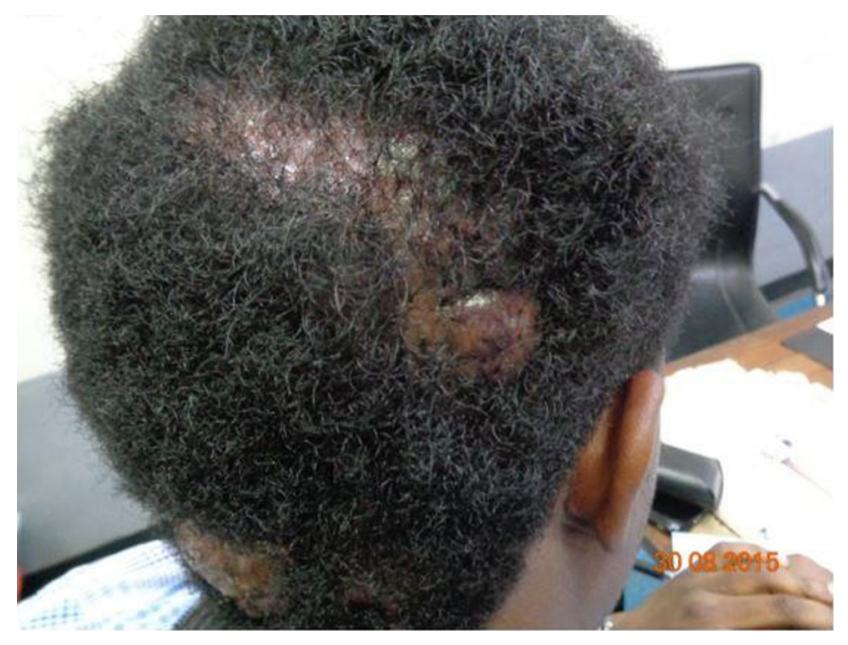

Figure 3 Occurrence of acne keloidalis and folliculitis decalvans.

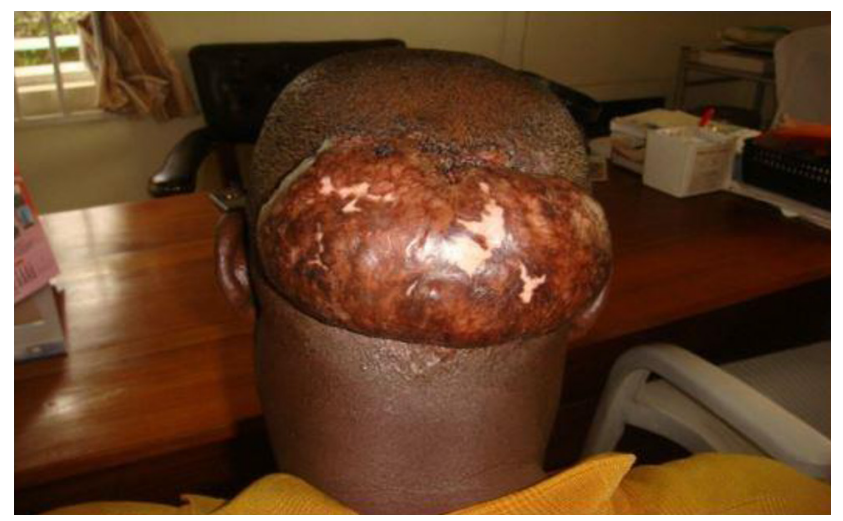

Figure 4 Huge keloidal lesion in nuchal and occipital region, which recurred after cryotherapy with quacks.

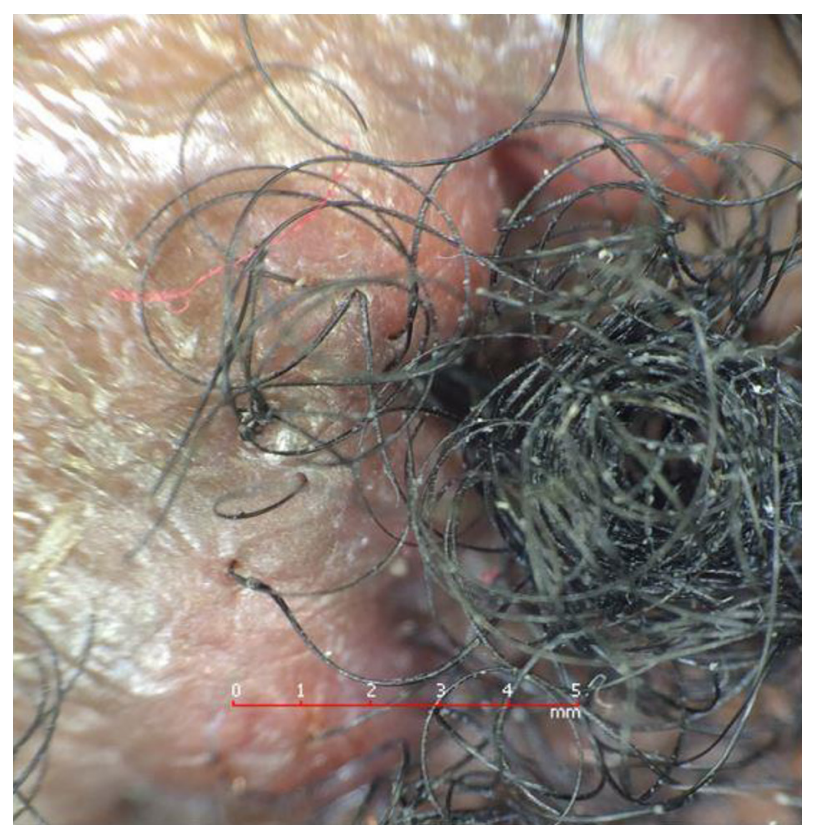

Figure 5 Loss of follicular ostia, tufted follicles, and papules $(\times 20)$.

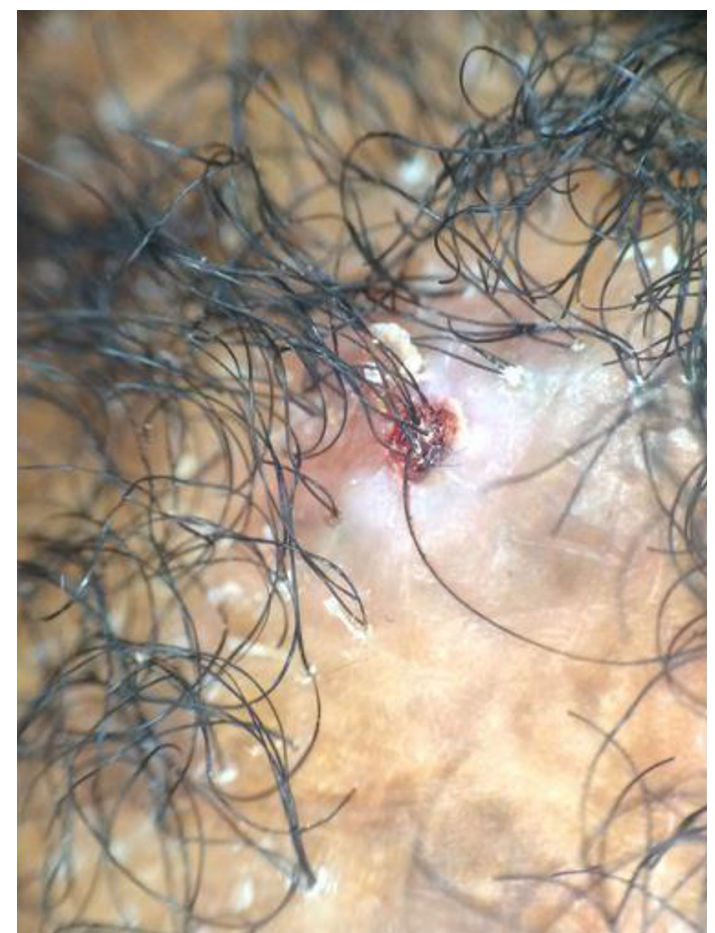

Figure 6 Tufted hairs with an area of loss of follicular ostia $(\times 20)$.

tumors. Treatment of AKN with caustic substances such as acids may result in the development of large lesions that are unsightly and affect the individuals' self-esteem. A previous report had associated AKN with the development of keloids elsewhere in the body but this is rarely seen. ${ }^{10}$ Repeated folliculitis predisposes to destruction of hair follicles and thus patchy alopecia. Keloidal masses are usually devoid of hair (Figure 4). Central centrifugal cicatricial alopecia and androgenetic alopecia may also occur in association with AKN. Dermoscopic features of early lesions of AKN may show hair shafts trapped in individual papules. Hair tufts may be seen especially when papules coalesce together forming larger lesions (Figures 5 and 6). There is also loss of follicular ostia as seen in other forms of scarring alopecia and ingrown hairs are absent.

\section{Management}

Management of AKN remains challenging especially in the developing countries. Unfortunately most of the men with AKN self-medicate or seek help from quacks, and only seek help from doctors when lesions become unsightly. Its perceived association with infection acquired from the barber's instrument has led to the use of a lot of antibiotics available over the counter possibly contributing to antibiotic resistance in the environment. Various corrosives such as acids and car engine oils are also used in the management of AKN. ${ }^{6}$ 


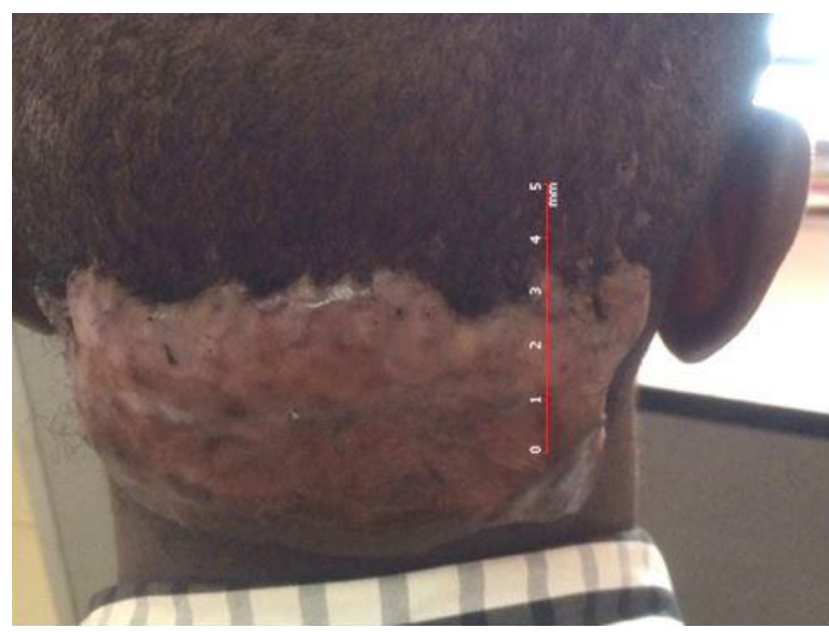

Figure 7 Huge fibrotic plaque with a few trapped hairs developing after application of caustic agent by quacks.

Liquid nitrogen is also available for use by quacks resulting in unsightly scars (Figure 7).

The goal of therapy is to prevent the development of the keloidal-like lesions and subsequent alopecia. Patients with AKN are more worried about the keloidal lesions than the alopecia. General measures include avoidance of irritation from frequent close shaves, helmets, and tight shirt collars. Individuals with $\mathrm{AKN}$ should be encouraged to avoid haircuts when lesions are active and bleed easily. The compulsion to shave the affected areas to ensure adequate absorption of topical medication should be discouraged as this further sets up more irritation. The use of antiseptic or tar containing shampoos may be useful in preventing secondary bacterial infections at this stage.

Reports of treatment modalities for AKN are based on case series; there is need for case-control studies to determine optimal treatment options in the management of this condition.

\section{Topical treatment}

Early or mild disease with non-keloidal lesions can be treated with potent topical steroids which may be combined with topical retinoids. Alternating topical steroid use, 2 weeks on and 2 weeks off and stepping down topical steroid strength have been known to reduce lesion count and side effects of long-term use of steroids. ${ }^{29}$ Topical clindamycin can be used alongside topical steroids when pustular lesions are present.

\section{Intralesional steroids}

Intralesional injections of long-acting steroids triamcinolone have been found useful in the management of mild to moderate forms of AKN. They can be used at a dose of $5-40 \mathrm{mg} / \mathrm{mL}$.
The higher steroid concentrations give a quicker response especially with early fibrotic lesions but tend to have more side effects such as hypopigmentation and atrophy. Dilution of the steroid reduces the chances of atrophy, and the accompanying transient hypopigmentation disappears after a while. ${ }^{30}$ Intralesional steroids can be painful especially if lesions are keloidal and extensive; however, injecting a ring of xylocaine around the lesions or diluting the steroids with xylocain makes the patient more cooperative and ensures the drug is giving adequately. Intralesional injections are given at intervals of 4 weeks.

Cryotherapy has been found useful in both early and keloidal lesions. It has been known to cause softening of keloidal lesions making intralesional injections easier. ${ }^{31,32}$

\section{Systemic therapy}

This involves the long-term use of antibiotics especially tetracycline derivatives and retinoids. The presence of pustules, sinuses, and fistula suggests secondary bacterial infection or associated folliculitis decalvans requiring antibiotics that are started at the same time with the steroids or a few days before initiating steroid therapy. Commonly used oral antibiotics include tetracycline derivatives such as deoxycycline, minocycline, and tetracycline that have antibacterial and anti-inflammatory effects. These drugs are useful in reducing inflammation and the effects of infection. ${ }^{30}$ The lesions on the vertex tend to respond faster, and there is a decrease in pain and bleeding although the fibrotic lesions may still remain. Oral retinoids have been found useful in patients with associated folliculitis decalvans and low doses may be continued for up to a year. ${ }^{33,34}$

\section{Surgical treatment}

This is reserved for individuals who do not respond to medical therapy or those with large fibrotic lesions. Punch biopsy needles are useful in removing fibrotic papules but should be deep enough to ensure that the whole follicle is removed so as to prevent a recurrence. Excision of a horizontal ellipse involving the posterior hairline extending to the subcutaneous tissue closed primarily or left to heal by secondary intention has been found useful. ${ }^{35,36}$ Electro and cryo surgeries have also been found useful for excising the fibrotic lesions. Healing of the wound by secondary intention has been found effective in patients with AKN, possibly leading to fewer recurrences. ${ }^{37}$ Postsurgical radiotherapy has been used in a patient to prevent recurrence. However, overall recurrence after surgical excision is low compared to what happens with actual keloids. 


\section{LASER and light therapy}

Treatment with $1064 \mathrm{~nm} \mathrm{Nd:} \mathrm{YAG} \mathrm{and} \mathrm{the} 810 \mathrm{~nm}$ diode lasers have been found useful in reducing lesion count and size in patients with AKN. ${ }^{35}$ The $1064 \mathrm{~nm}$ Nd: YAG destroys the hair follicles within the lesions which has some bearing on the inflammation. ${ }^{38}$ It can be used in conjunction with topical steroids or retinoids and has been found useful in refractory cases. Excision by carbon dioxide laser has also been reported to improve lesions of $\mathrm{AKN}^{39-41}$

Targeted ultraviolet $\mathrm{B}$ radiation was also found to be useful in improving the appearance of fibrotic papules. ${ }^{42}$ The treatment was well tolerated, and there was some improvement after 16 weeks of therapy. It was however not as effective as the laser treatment.

\section{Prognosis}

Early lesions respond to medical treatment with minimal scarring. Surgical excision with healing with secondary intension tends to be effective in management. The $1064 \mathrm{~nm} \mathrm{Nd:}$ YAG and $810 \mathrm{~nm}$ diode lasers have been found effective and promising in the management of AKN but are unaffordable by many in this environment.

\section{Prevention}

Young male adults should avoid frequent close shaves especially on the nuchal area of the scalp. Other factors that may lead to irritation such as the use of tight helmets, tight shirt collars, and wooden combs should be avoided. Individuals prone to AKN should seek help early so as to prevent huge keloidal masses and unsightly scarring. Bleeding of inflamed lesions does occur. There is an urgent need to ensure that young men in developing countries practice safer shaving habits so as to limit the spread of blood-borne infections.

In conclusion, $\mathrm{AKN}$ is a form of chronic folliculitis of the scalp resulting in alopecia, unsightly scars, and keloidal lesions. It is presently believed to be primary disorder of scarring alopecia with possibly multiple precipitating factors.

Medical therapy has been found useful in mild cases while surgical excision and laser and light therapy have been found useful in the management of severe lesions. Unfortunately, the later is not affordable in low resource settings in which $\mathrm{AKN}$ is prevalent. There is a need to educate young men on the possible contributing or exacerbating factors so as to reduce its occurrence and severity. Individuals with AK should be advised to seek help early so as to prevent the development of unsightly lesions that affect the self-esteem of individuals affected.

\section{Disclosure}

The author reports no conflicts of interest in this work.

\section{References}

1. Dinehart SM, Herzberg AJ, Kerns BJ, Pollack SV. Acne keloidalis: a review. J Dermatol Surg Oncol. 1989;15(6):642-647.

2. Gloster HM Jr. The surgical management of extensive cases of acne keloidalis nuchae. Arch Dermatol. 2000;136(11):1376-1379.

3. Adamson H. Dermatitis papillaris capillitii (Kaposi): acne keloid. $\mathrm{Br}$ Dermatol. 1914;26:69-83.

4. Fox H. Folliculits keloidalis a better term than dermatitis papillaris capillitii. Arch Dermatol Syphilol. 1947;55:112-113.

5. Olsen EA, Bergfeld WF, Cotsarelis G, et al. Summary of North American Hair Research Society (NAHRS)-sponsored workshop on Cicatricial alopecia, Duke Medical Centre, February 10 and 11, 2001. J Am Acad. 2003;48(1):103-110.

6. Ogunbiyi AO, Adedokun B. Perceived etiological factors of folliculitis keloidalis nuchae and treatment options amongst Nigerian men. $\mathrm{Br} J$ Dermatol. 2015;173(Suppl 2):22-25.

7. Azurdia RM, Graham RM, Wesmann K, Guerin DM. Acne keloidalis in Caucasian patients on cyclosporine following organ transplantation. Br J Dermatol. 2000;143(2):465-467.

8. Ogunbiyi AO, George AO. Acne keloidalis in females; case report and review of literature. JNMA. 2005;97:736-738.

9. Dinehart SM, Tanner L, Mallory SB, Herzberg AJ. Acne keloidalis in women. Cutis. 1989;44:250-252.

10. Salami T, Omeife H, Samuel S. Prevalence of acne keloidalis nuchae in Nigerians. Int J Dermatol. 2007;46:482-484.

11. Ogunbiyi AO, Daramola OO, Alese OO. Prevalence of skin diseases in Ibadan, Nigeria. Int J Dermatol. 2004;43(1):32-36.

12. Ogunbiyi AO, Owoaje E, Ndahi A. Prevalence of skin diseases in school children. Pediatr Dermatol. 2005;22:6-10.

13. Adegbidi H, Atadokpede F, do Ango-Padonou F, Yedomon H. Keloid acne of the neck: epidemiological studies over 10 years. Int J Dermatol. 2005;44(Suppl 1):49-50.

14. Khumalo NP, Jessop S, Gumedze F, Ehrlich R. Hair dressing is associated with scalp disease in African school children. Br J Dermatol. 2007;157:106-110.

15. Child FJ, Fuller LC, Higgind EM, Du Vivier AW. A study of the spectrum of skin disease occurring in the black population in South East London. Br J Dermatol. 1991;141:512-517.

16. Knable AL Jr, Hanke CW, Gonin R. Prevalence of acne keloidalis nuchae in football players. J Am Acad. 1997;37(4):570-574.

17. George AO, Akanji AO, Nduka EU, Olasode O. Clinical biochemistry and morphological features of acne keloidalis in a black population of acne keloidalis in a black population. Int J Dermatol. 1993;32(10):714-716.

18. Kelly AP. Psuedofolliculitis barbae and acne keloidalis nuchae. Dermatol Clin. 2003;21(4):645-653.

19. Sperling LC, Homoky C, Prat L, Sau P. Acne keloidalis is a form of primary scarring alopecia. Arch Dermatol. 2000;136:479-484.

20. Smith JD, Odom RB. Pseudofolliculitis of the beard. Arch Dermatol. 1977; 113:28-329.

21. Winter H, Schissel D, Parry D, et al. Unusual Ala12Thr polymorphism in the 1A-helical segment of the companion layer-specific keratin K6hf: evidence for a risk factor in etiology of the common hair disorder pseudofolliculitis barbae. J Invest Dermatol. 2004;122:652-657.

22. Herberg A, Dinehart S, Kerns B, Pollack S. Acne keloidalis: transverse microscopy, immunohistochemistry and electron microscopy. Am J Dermatopathol. 1990;12:109-121.

23. Al-Zaid T, Vanderwell S, Genbowic A, Lyle S. Sebaceous gland loss and inflammation in scarring alopecia: a potential role in pathogenesis. $J$ Am Acad Dermatol. 2011;65:597-603.

24. Grunwals MH, Ben-Dor D, Livini E, Halevy S. Acne keloidalis-like lesions $\mathrm{n}$ the scalp associated with antiepileptic drugs. Int J Dermatol. 1990;29(8):559-561. 
25. Wu WY, Otberg N, McElwee KJ, Shapiro J. Diagnosis and management of primary cicatricial alopecia: part II. Skinmed. 2008;7(2):78-83.

26. Verma SB, Wollina U. Acne keloidalis nuchae; another cutaneous symptom of metabolic syndrome, truncal obesity and impending overt diabetes mellitus. Am J Clin Dermatol. 2010;11(6):433-436.

27. Adekanle O, Ndububa DA, Ayodeji O, Paul-Odo B, Foloruso TA. Sexual transmission of the hepatitis donors in a tertiary hospital in Nigeria. Singapore Med J. 2010;51:944-947.

28. Khumalo NP, Gumedze F, Lehloenya L. Folliculitis keloidalis is associated with the risk of bleeding hair cuts. Int J Dermatol. 2011;50: 1212-1216.

29. Callender VD, Young CM, Haverstock CL, et al. An open label study of clobetasol propionate $0.05 \%$ and betamethasone valerate $0.12 \%$ foams in treatment of mild to moderate acne keloidalis. Cutis. 2005;75(6): 317-321.

30. Alexis A, Heath C, Halder RM. Folliculitis keloidalis nuchae and psuedofolliculitis barbae. Are prevention and effective treatment within reach? Derm Clin. 2014;32:183-191.

31. Layton AM, Yip J, Cunliffe WJ. A comparison of intralesional triamcinolone and cryosurgery in the treatment of acne keloids. Br J Dermatol. 1994;130(4):498-501.

32. Pasquali P. Cryosurgery in Dermatologic Surgery; Step by Step. 1st ed. UK: John Wiley and Sons; 2013

33. Goh MSY, Magee J, Chong AH. Keratosis follicularis spinulosa decalvans and acne keloidalis nuchae. Aust J Dermatol. 2005;46(4):257-260.
34. Janjua SA, Iftikhar N, Pastar Z, Hosler GA. Keratosis follicularis spinulosa decalvans associated with acne keloidalis nuchae and tufted hair folliculitis. Am J Clin Dermatol. 2008;9(2):137-134.

35. Beckett N, Lawson C, Cohen G. Electrosurgical excision acne keloidalis with secondary intention healing. $J$ Clin Aesthet Dermatol. 2011;4(1):36-39.

36. Glenn MJ, Bennett RG, Kelly AP. Acne keloidalis nuchae treatment with excision and secondary intention healing. J Am Acad Dermatol. 1995;33(1):243-246.

37. Bajaj V, Langtry JA. Surgical excision of acne keloidalis nuchae with secondary intention healing. Clin Exp Dermatol. 2008;33:53-55.

38. Maranda EL, Simmons BJ, Nguyen AH, Lim VM, Keri JE. Treatment of acne keloidalis nuchae: a systematic review of literature. Dermatol Ther (Heidelb). 2016;6:363-378.

39. Millian-Cayetano JF, Repiso-Jimenez JB, Del Boz J, de Troya-Martin M. Refractory acne keloidalis nuchae treated with radiotherapy. Aust J Dermatol. 2015.

40. Esmat SM, Abdel Hay RM, Abu Zeid OM, et al. The efficacy of laserassisted hair removal in the treatment of acne keloidalis nuchae: a pilot study. Eur J Dermatol. 2012;22(5):645-650.

41. Kantor GR, Ratz JL, Wheeland RG. Treatment of acne keloidalis nuchae with carbon dioxide laser. JAm Acad Dermatol.1986;14:263-267.

42. Okoye GA, Rainer BM, Leung SG, et al. Improving acne keloidalis nuchae with targeted ultraviolet $\mathrm{B}$ treatment: a prospective, randomized split-scalp study. Br J Dermatol. 2014;171(5):1156-1163.
Clinical, Cosmetic and Investigational Dermatology

\section{Publish your work in this journal}

Clinical, Cosmetic and Investigational Dermatology is an international, peer-reviewed, open access, online journal that focuses on the latest clinical and experimental research in all aspects of skin disease and cosmetic interventions. This journal is included on PubMed. The manuscript management system is completely online

\section{Dovepress}

and includes a very quick and fair peer-review system, which is all easy to use. Visit http://www.dovepress.com/testimonials.php to read real quotes from published authors 